\title{
REFINEMENTS OF THE HERON AND HEINZ MEANS INEQUALITIES FOR MATRICES
}

\author{
ILYAS Ali, Hu YANG AND ABdul SHAKOOR
}

Abstract. This article aims to present some unitarily invariant norms inequalities involving Heron and Heinz means for matrices. We give some refinements for the results presented by R. Kaur and M. Singh in [Math. Ineq. Appl., 16 (2013) 93-99].

Mathematics subject classification (2010): 47A30, 15A60.

Keywords and phrases: Unitarily invariant norms, Positive definite matrices, Convex function, Heron means, Heinz means.

\section{REFERENCES}

[1] R. BHATIA, C. DAVIS, More matrix forms of arithmetic-geometric mean inequality, SIAM J. Matrix Anal. Appl. 14 (1993), 132-136.

[2] R. Bhatia, Matrix Analysis, Springer-Verlag, New York, 1997.

[3] R. Bhatia, R. Sharma, Some inequalities for positive linear maps, Linear Algebra Appl. 436 (2012), 1562-1571.

[4] R. KaUR, M. Singh, Complete interpolation of matrix versions of Heron and Heinz means, Math. Ineq. Appl. 16 (2013), 93-99.

[5] S. WANG, L. Zou, Y. Jiang, Some inequalities for unitarily invariant norms of matrices, J. Inequal. Appl. 2011, 2011:10. 